\title{
CONCIENCIA, CONCEPTOS Y AUTONOMÍA: § 8
}

\section{CONSCIOUSNESS, CONCEPTS AND AUTONOMY: \\ $\S 8$}

\author{
EDGAR MARAGUAT \\ Universitat de València
}

La sección octava del manuscrito de Krause que contiene sus notas de las lecciones sobre la Doctrina de la Ciencia «según su nuevo método» - las impartidas el semestre de invierno de 1798-1799- se dedica a avanzar hacia la contestación de una pregunta que se plantea al comienzo de varios modos. ¿Cómo es posible un concepto del libre actuar? ¿Cómo es posible el yo para sí mismo? ¿Cómo debe ser referida la intuición al yo? ¿Cómo puede estar ahí el yo para sí? (cf. WLnm-K, GA IV/3, 393 s. ${ }^{1}$ ). En el contexto de las lecciones, dado que «una intuición referida al yo» es la caracterización literal de un «concepto", se puede decir que las tres últimas cuestiones - las que de hecho merecerán una atención inmediata en la sección - interrogan por la posibilidad de un concepto, por de pronto empírico. ¿Cómo es posible que el yo no esté 'perdido' en la intuición de lo rojo o lo salado, sino que él sea ahí (también) para sí, o que la intuición sea, después de todo, referida a él y a él remita?

Lo que sigue ha de ser, fundamentalmente, un comentario a esa sección (el § 8). He de advertir que no será un comentario «deletreador», línea por línea o palabra por palabra, pues de serlo, pudiendo servir a otros fines, no serviría igual de bien, creo, a un comentario en conjunto - aunque cooperativo- a las leccio-

\footnotetext{
${ }^{1}$ Si no indico expresamente lo contrario, cito o remito a lo largo del texto a este volumen de la Gesammtausgabe (GA) de la Academia Bávara de las Ciencias, en que se contienen los apuntes tomados por Karl Ch. F. Krause de las lecciones.
} 
nes. Éste será un comentario sobre su contenido general y su situación en el curso de Fichte ${ }^{2}$.

Un comentario de esta índole se recomienda por varios motivos. El mayor de ellos tiene que ver con la unidad de la obra. La obra tiene por tema una única dificultad y todas las cuestiones que aborda en serie son problemas que apuntan a ese único nudo. El $§ 8$, de hecho, se asoma a la estructura de matryoshka de las dificultades de las lecciones: cada una de las examinadas sucesivamente está en el corazón de una única gran dificultad, que a todas abarca. La tarea general no se resuelve por medio de la conquista progresiva de un terreno, pues ninguna porción está asegurada hasta que se ha llegado al final.

\section{Consideraciones preliminares}

Empezaré recordando las líneas maestras de la tarea que Fichte se impone. Pero téngase bien en cuenta que lo que ahora diré no puede ser un simple recordatorio, pues todo ello es controvertido. Para empezar por el principio, diré que a mi juicio el tema del curso es la posibilidad de la conciencia y, por tanto, no estricta ni exclusivamente la ciencia. « ¿Cómo es posible la conciencia? Esa es nuestra pregunta principal» (435; cf. 439). El tema de la doctrina no es la opinión garantizada o con garantías, la episteme platónica, sino la opinión misma, al menos en tanto que tiene contenido u objeto, presenta un mundo o, por decirlo figurativamente, nos lleva fuera de nosotros mismos. Es Fichte mismo, por cierto, quien recurre a esta imagen de la salida de uno mismo $(429,484)$, por lo demás corriente en la época.

\footnotetext{
${ }^{2}$ He de agradecer a Salvi Turró y a Manuel Jiménez la confianza que me han transmitido para optar por subrayar algunos aspectos aporéticos de las lecciones de Fichte. Asimismo, he de agradecerle una vez más a Jacinto Rivera de Rosales la invitación a participar en las actividades de la Red Ibérica de Estudios Fichteanos, amén de su estimulante trabajo de traducción e interpretación de los textos de Fichte (en particular su magnífica edición de la Ética, una obra contemporánea de la nova methodo de Krause), y a él, a Mariano Gaudio y a Ramón Coletas los comentarios que hicieron a una versión previa de este trabajo. También he de reconocer el apoyo material que me han brindado las subvenciones del MICINN a los proyectos Consolider-C HUM2006-8236 y FFI2009-09686.
} 
La alternativa principal a esta presentación es, fundamentalmente, la siguiente: ¿cómo es posible la autoconciencia? Ésta parece a menudo y a muchos la preocupación nuclear de Fichte en la Doctrina de la Ciencia. Pero en mi opinión se le hace justicia al texto diciendo que la cuestión sin duda central por la posibilidad de la autoconciencia hay que verla, para empezar, como un aspecto - a todas luces primordial, ciertamente- de la respuesta a la cuestión por la conciencia: dado que tener conciencia genuinamente es ser sabedor, hace falta aislar un punto de vista o sujeto de la conciencia para explicar la conciencia, de forma que la investigación de la autoconciencia hay que verla como un medio de la investigación de la conciencia o, dicho de otro modo, hay que reconocer que con la deducción de la autoconciencia contribuimos a deducir toda conciencia.

A mi modo de ver estamos sin más, en realidad, ante la vía kantiana de la primera Critica, si bien en la Wissenschaftslehre se ha atenuado notablemente el interés estrictamente epistemológico, esto es, el interés por entender el éxito del programa cartesiano que realizan los Principia de Newton ${ }^{3}$. Por una parte, se trata, como es sabido, de elevarse al principio de la filosofía trascendental o, concretamente, de comprender mejor el papel de la «unidad de la autoconciencia» en la constitución de toda conciencia, precisamente como condición suprema de ésta. Y por otro, como para Kant, hay que asegurar ante todo la referencia o validez objetiva de las representaciones: que el orden de las representaciones no sea el orden en que nos representamos algo, sino el orden de algo que es representado.

Estos fines no deben ocultar, no obstante, que de hecho el grueso de la obra es una aclaración conceptual de la subjetividad. Mi temor es, más bien, el contrario: que ese grueso oculte el hecho de que lo que debe ser explicado, en última instancia, es el avistamiento del mundo (cf. 430). Al fin y al cabo, Fichte advierte en la introducción a las lecciones que la elevación a la Filosofía la produce la pregunta por la existencia de cosas efectivas al margen de la representación y que la contestación científica de esta pregunta es de hecho la Filosofía (324).

\footnotetext{
${ }^{3}$ Claro que transitar la calzada kantiana no significa, simplemente, reescribir o corregir la Crítica, pues las ambiciones de Fichte van más lejos que las de Kant: son, al fin y al cabo, sistemáticas, no sólo críticas, y ello implica ir más 'atrás' que Kant buscando un principio del saber e ir más allá de Kant buscando una articulación y concreción del todo del saber.
} 
¿Cómo se aborda, por cierto, tal pregunta? Sabido es que Fichte adopta un punto de vista que denomina y denominamos, siguiendo a Kant, trascendental. Esto significa, en negativo, que la deducción de la conciencia que se promete y ensaya no consistirá en una, digamos, historia natural de la conciencia, es decir, en una exposición de la génesis histórica o psicológica de la conciencia.

En positivo esto quiere decir al menos otras dos cosas. En primer lugar, que se parte de la conciencia como de una premisa más allá de la cual se cree que sólo se puede ir — hasta lo que Fichte llama yoidad (o inteligencia o razón)— para entender su constitución o mecanismo y deducirla, no para derivarla o verla producirse, so pena de incurrir en un punto de vista, que Fichte llama "dogmático», al que le está vedada la aclaración de sí mismo ${ }^{4}$. Ir más allá de la conciencia para verla producirse es, en opinión de Fichte, tomar un desvío que nunca nos devolverá a la senda por la que queríamos avanzar. "Captarse a sí mismo sólo lo puede hacer la conciencia libre» (ZE, GA I/4, 261). Y que hay tal cosa, felizmente, es algo que (sólo) tenemos que reconocer. «Ahora bien, la conciencia existe [Nun ist aber doch Bewusstseyn]» (VND, GA I/4, 275), sentencia Fichte, en un arranque que recuerda al de Kant años atrás reconociendo - e invitado a reconocerque hay, de la naturaleza, ciencia.

No obstante, esto no quiere decir que se parte de algo «dado», de un hecho de la conciencia, por ejemplo, como Reinhold había propuesto (aunque, como veremos ocasionalmente, la cuestión de si así es después de todo es difícil de dirimir). Si acaso se parte de un postulado (344 ss.), de una tarea o trabajo, en el sentido de algo que se hace o se lleva a cabo y que los demás, en particular los oyentes, han de poder hacer también (reproducir, literalmente). Para Fichte es tan inapropiado decir que se parte de algo dado como decir lo contrario, que se parte de algo fingido, ideado o, digamos, tramado. Esto recomienda, seguramente, el neologismo célebre: la Wissenschaftslehre parte de una "acción de hecho" (Thathandlung), esto es, de una acción a la que se ha dado siempre ya cumplimiento, que en efecto se ejerce o pone en acto, y no de un simple hecho o resultado (Thatsache). Fichte dice explícitamente que la Doctrina parte de que lo intuyente (lo

\footnotetext{
${ }^{4} \mathrm{La}$ "premisa» a la que me refiero se indica con precisión, por ejemplo, en este pasaje del comienzo de la Ética: «Yo me encuentro actuando efectivamente en el mundo sensible. De ahí parte toda conciencia, y sin esa conciencia de mi actividad eficiente no habría autoconciencia alguna, [y a su vez] sin ésta, ninguna conciencia de otra cosa distinta de mí» (SSL, GA I/5, 22; mi énfasis).
} 
que capta o recibe) y lo hacedor (lo productor) son uno y lo mismo (363), a la vez contra el intento dogmático de comprender lo hecho a partir de lo dado y contra el intento idealista de comprender lo dado a partir de lo hecho5.

El punto de vista es trascendental, en segundo lugar, porque las explicaciones que se ofrecen en las lecciones no van más allá de la «inteligencia» y, por tanto, no son válidas «en sí». Pero, entiéndaseme, esto no significa que su validez sea limitada, ya que, según Fichte, el punto de vista de «lo en sí» es ininteligible o absurdo (356), la idea misma de cosa en sí ha de ser «superada» (372) y, por tanto, no resta otra validez para otro argumento (cf. GWL, GA I/2, 368 s.). Un modo de resumir cuál es el punto de vista, no exento de paradoja, es el que años atrás proporciona la primera versión de las lecciones: la Doctrina — aclara el Fundamento de 1794- muestra de lo que hay que explicar (das zuerklärende) que (daß) no se puede explicar y por qué (warum) no se puede explicar (GWL, GA $\mathrm{I} / 2,311)$. Lo que hay que explicar es la constitución o configuración de la conciencia; cosa que no se podría "explicar» si, para explicarla, hubiera que retrotraer la conciencia a un fundamento ajeno a ella.

Este punto de vista trae consigo un método determinado. Puesto que hay que esclarecer la posibilidad de la conciencia y la autoconciencia es su condición de posibilidad suprema, la obra asciende en un primer tramo hasta esa condición -hasta, aproximadamente, el $§ 13$ (cf. 447) - y luego desciende para mostrar en efecto cómo la constitución en detalle de la conciencia ha quedado por la autoconciencia posibilitada — desde el $§ 14$ aproximadamente. Ésta es, desde luego, una de las articulaciones más sobresalientes del texto, que en conjunto muestra que el fundamento de la conciencia no hay que buscarlo en las cosas, sino, agustinianamente, en uno mismo.

No obstante, hay en las lecciones una inflexión, si cabe, más interesante todavía. Puesto que desde el principio sabemos qué inteligibilidad es la que nos preocupa, hemos de poder, siquiera sea preliminarmente, exponer la conciencia —el ser sabedor- en su peculiar «facticidad» y, en efecto, la obra arranca presentando la intuición del yo, que viene a ser el único objeto que puede intuirse sin que la

\footnotetext{
${ }^{5}$ Estas categorías son, como es sabido, las que articulan la noción kantiana de experiencia en la Crítica de la razón pura y, a partir de ella, el debate postkantiano sobre la conciencia y el conocimiento (cf. B 1).
} 
posibilidad de su intuición parezca que haya que buscarla fuera de él. La dilatación de la intuición intelectual del yo, que constituye el comienzo del curso, se contradistingue de la tarea de concebir lo intuido en ella, y toda otra división de las lecciones es interior a la realización de esa tarea.

Este paso de la intuición al concepto lo contiene el $§ 1$ (un paso que, por cierto, en el manuscrito de Halle se dice que es el paso de la acción de hecho al hecho: WLnm-H, GA, IV/2, 33; del «hecho», sin embargo, sólo empieza a hablarse en WLnm-K al final del $\S 4)^{6}$. En el $\$ 2$ - dedicado a la deducción del no-yo a partir del yo- se dice que ya no se ha partido —entiéndase, en él一 de lo inmediato mismo, sino de una representación de ello: «La conciencia a partir de la cual hemos argumentado ahora no es inmediata, es REPRESENTACIÓN de la [conciencia] inmediata, pero no la [conciencia] inmediata misma» (353).

El $§ 2$ prueba entonces que si el yo ha de volver a ser objeto de nuestra conciencia, hemos de sentar un no-yo. Con él empieza el análisis de aquello que ha de ocurrir para, digamos, sentar conceptual y discursivamente el yo (Fichte encadena en las lecciones una serie de "teoremas intermedios» que permitirían, supuestamente, resolver la tarea). Esa representación del yo (y el no-yo) es una representación libre —obra del libre albedrío — que nos hacemos al filosofar por medio de una reflexión a cuya espalda queda el ojo que mira el ver del ojo, según la metáfora conocida, como no podía ocurrir en la intuición del comienzo (345, 365 s. $^{7}$.

Pero téngase presente que el no-yo no se postula como una hipóstasis, sino que el no-yo es «la conciencia inmediata misma», bien que no intuida, sino concebida, y no como actividad, sino como reposo o quietud (355). De entrada trátase ahora del yo mismo tomado como sustancia, del que en el fondo, en fin, nunca saldremos o del que saldremos simplemente para contemplar dos aspectos suyos (cf. 377), pues «salir» no hace ninguna falta — piensa Fichte- para derivar «la representación del mundo». Tal es la inversión —y sistematización-

\footnotetext{
${ }^{6}$ El propio Fichte hace saber que una de las diferencias principales entre las lecciones y la Wissenschaftslehre publicada se halla al comienzo: en las lecciones se habría ido del concepto a la intuición y aquí, ya digo, al revés.

${ }^{7}$ Cf. 361 s., donde se dice que se ha contestado a la pregunta «cómo llega el Yo a salir de la conciencia inmediata y a configurar en sí la conciencia».
} 
de Spinoza que opera la Doctrina: «el No-Yo no es nada más que otro modo de ver el Yo» (356; cf. GWL, GA I/2, §3, passim) ${ }^{8}$. Lo único que se intuye inmediatamente es el actuar del yo, todo lo demás, mediatamente: «Todo lo que vemos lo vemos en nosotros, [y] sólo nos vemos a nosotros en tanto que hacemos (nur als handelnd), en tanto que transitamos de lo determinable a lo determinado» (366).

A la vista de esta articulación, la que considero mayor, puede decirse que las lecciones no tienen la estructura general de una escalera de tijera, que subiríamos hasta el $\S 13$ y bajaríamos a continuación, sino, para bien y para mal, la estructura de un círculo. Para bien porque la aspiración de Fichte lo es a una aclaración completa (gesammte) y discursiva de la conciencia, que no parte de hechos, ni de hechos de la conciencia misma ni de la facultad de juzgar. Para mal porque el modo en que comienza a trazarse el círculo, a saber, intuyendo e invitando a intuir, hace inverosímil que la aclaración lo sea del comienzo mismo y, por ello, pone en evidencia las limitaciones de la concepción misma de su particular intento de volver al principio (claro que Fichte, al fin y al cabo, no siente empacho en reconocer que la Doctrina arranca en un punto del que no cabe demostración o cosa semejante).

De hecho, llega a advertirse en las lecciones que el concepto de acción del que se parte (en que de él se parte insiste la «Segunda Introducción a la Doctrina de la Ciencia») no ha de ser explicado, siendo como somos «inmediatamente conscientes» de él, y el de yo se aclara completamente por medio de él (345; cf. 355), así como el de no-yo o actividad cancelada (357). Son confesiones como éstas las que justifican, hasta cierto punto al menos, los malintencionados comentarios de Hegel sobre un fichteano comienzo por lo consabido?

\footnotetext{
${ }^{8}$ Cf. GWL, GA I/2, 263 s. Spinoza es un blanco reconocido del argumento general de la primera Critica y un referente fundamental en las obras de Fichte, Schelling y Hegel que tratan de trascender los aspectos empiristas de esa obra. El primer escrito sistemático de Schelling —Vom Ich als Princip der Philosophie oder über das Unbedingte im menschlichen Wissen- es un monumento a la inversión del spinozismo (Schelling abrigó por entonces el proyecto de una nueva Ética à la Spinoza).

${ }^{9}$ Véase G. W. F. Hegel, Ciencia de la lógica. Volumen I: La lógica objetiva, trad. de Félix Duque, Madrid, Abada Editores, 2011, pp. 220 s.
} 
No obstante, hay que reconocerle a Fichte que, más allá del $§ 1$, asistimos a un ambicioso e industrioso tour de force, en muchos sentidos sin precedentes, para dar alcance al pensamiento del acto de libertad en que se dice que consiste un comienzo absoluto $^{10}$. El $\S 3$ indica que, aunque lo primero propiamente real es (la) libertad, en el "pensamiento» no puede plantearse así de entrada (kann es nicht zuerst aufgestellt werden), esto es, como primero, de modo que hemos de llegar a ello a través de nuestras investigaciones (363). Con avisos como éste se suaviza la impresión de pistoletazo o, mejor, tajo de Alejandro que producen las lecciones al comienzo (esta segunda imagen se la aplica a sí mismo Fichte en GWL, GA I/2, 300 s.).

La discusión de la organización de la obra se puede complicar aún más a la vista del contenido de los $\$ \$ 2-5$, en que Fichte sienta las bases sobre las que concebir el problema a resolver (fundamentalmente las nociones de actividad real e ideal y las de lo determinable y lo determinado). Brevemente el problema a solucionar puede enunciarse de la siguiente manera. Yo mismo sólo soy objeto de la conciencia en el actuar y, por ello, la cuestión "cómo es posible la conciencia» nos arrastra a la cuestión "cómo puedo hacerme consciente de mi actuar», cuya respuesta fichteana, rigurosamente kantiana, viene a ser: por medio del concepto de un fin incondicionado. Sin el concepto de un fin incondicionado no es seguro que lo que tomo por $m i$ actuar sea en efecto $m i$ actuar y, por tanto, no es seguro que lo que parece conciencia sea conciencia.

Cuando se han sentado esas bases, Fichte escribe: «A partir de ahora hemos de ofrecer la posibilidad de lo establecido hasta aquí» (373) y "ya tenemos a la vista la culminación». Y añade en qué consistirá el clímax del curso: «Cuando lleguemos al punto en el que comprendemos que el Yo se pone a sí mismo como puesto por sí mismo, nuestro sistema estará acabado, y este será el caso [cuando lleguemos] al querer».

El problema general —el problema, digamos, de la gran muñeca- es el que plantea la comprensión del querer, en el sentido paradójico que tiene el querer: comprender cómo algo puede sentarse como sentado por sí mismo o, dicho de

\footnotetext{
${ }^{10}$ El avistamiento del desafío, claro está, tiene muchos precedentes, que se remontan como poco al De libero arbitrio de Agustín de Hipona.
} 
otro modo, comprender cómo algo puede ser visto como limitado (decidido), pero sólo porque se ha así (y a sí) limitado, y, a la vez, comprender cómo puede verse algo que se ha limitado a sí mismo como algo limitado. «¿Cómo es posible un concepto del libre actuar?», recuérdese, es el interrogante que se plantea, antes que ningún otro, en el $\$ 8$, pero no porque el $\S 8$ tenga que abordarlo o contestarlo, sino porque es el interrogante que resume cualquier otro, también los interrogantes a los que sí se dedica el $§ 8$, y por tanto el que tiene que abordar y resolver la obra total (cf. 380: «La acción libre es lo más esencial de nuestra investigación»; cf. 384).

Para acabar con estas consideraciones preliminares añadiré que este problema, para Fichte, tiene sólo la apariencia de un problema específicamente práctico. Las nuevas lecciones revelan una nueva clarividencia sobre el hecho de que el problema del reconocimiento del yo en la acción —es decir, de la concepción misma de la acción - no es un problema ni teórico ni práctico, es el problema de toda acción y, como la conciencia se explica a partir de la intuición de la acción, es el problema de toda conciencia, teórica y práctica. Esta nueva unidad de la Doctrina, como veremos, tiene una consecuencia expositiva fundamental en el parágrafo que comentaré y los que lo preceden inmediatamente.

\section{De la intuición empírica al concepto}

El ascenso a la comprensión de un concepto de acción incondicionada, ascenso que Fichte entiende, como Kant, que permitirá la comprensión del carácter absoluto de la razón, pasa por una discusión previa de la noción misma de concepto y, antes, de contenido del concepto. De la intuición empírica como contenido de un concepto, o, mejor, de lo sensible —el sentimiento- y lo objetivo en la intuición y de la concepción de la intuición tratan sucesivamente los $§ \S 6-8$. El $\S 6$ se dedica al sentimiento (Gefühl), el $§ 7$ a la intuición (Anschaunng) y el $§ 8$ al concepto (Begriff).

Pero Fichte no acomete un estudio psicológico de la sensibilidad y sus operaciones en las lecciones, al modo, por ejemplo, aristotélico (no más que Hume en su Enquiry y aún menos que Kant en la Kritik). Concentra su atención, más bien, en mostrar que toda conciencia debuta con la puesta en juego de conceptos, sin negar — como tampoco hizo Kant-que todo conocimiento «empieza por la 
experiencia». Su interés, por tanto, es aquí filosófico. Y su posición general es antiempirista y, para más señas, idealista: no ocurre que todo pensamiento es una impresión desvaída, de poca vivacidad, sino, al revés, que toda impresión llega a ser impresión sólo y en la medida en que es pensada o se reflexiona sobre ella. Éste también es, desde luego, un motivo kantiano, pero las ambigüedades de la Crítica - que todavía hablaba de representaciones que de suyo produce la afección de los sentidos (B 1) — se han dejado atrás, al menos hasta cierto punto (en la última sección volveré sobre esto). Del sentimiento se sigue todo de suyo (403), pero a su mero surgimiento le pertenece que el yo, por así decir, se 'mueva' en su contra (un esfuerzo, una iniciativa del yo). O como se había dicho en la Grundlage: «Sin actividad del yo no hay Anstoss [que valga]» (GWL, GA I/2, 356).

Las nociones de sentimiento, intuición (empírica) y concepto (empírico) de los $\S \S 6-8$ son entendidas a partir de las nociones de actividad ideal y real que se introducen en el $\S 3$, por lo que es necesario recordar brevemente cuál es el perfil fichteano de éstas para entender aquéllas. En principio la actividad real es sin más actuar, acción real o práctica, y la actividad ideal se presenta como actividad figuradora (abbildende), reproductora (nachmachende) o contempladora (zusehende) de la otra. No obstante, Fichte indica con insistencia que, conceptualmente, se condicionan recíprocamente, es decir, que se comprenden la una por la otra (cf. 361). La actividad real sólo es tal "por medio" del yo (cf. 379 s.) y para ello ha de ser también ideal. Mientras la actividad ideal — que se define como una actividad sentada por el yo que ha vuelto a ser objeto de la reflexión y se ha vuelto a representar por medio de una actividad ideal y que se postula con el yo- es una actividad que se ha vuelto objeto por la actividad real (toda limitación que se presenta en la conciencia debe partir de la actividad práctica, se lee en 367$)^{11}$.

Las relaciones entre sentimiento, intuición y concepto resultan de esta relación general entre la actividad real y la ideal. De hecho, Fichte llama «sentimiento» a un padecer real o limitación de la actividad real. Es un estado determinado del

\footnotetext{
${ }^{11}$ Huelga decir que esa definición de la actividad ideal es en sí misma problemática (por no decir circular), pues apunta hacia una reflexión infinita (que es objeto de reflexión, que es objeto de reflexión, etc.; cf. 402), y que la obra tiene que desbaratar o resolver el problema de este retroceso indefinido (problema que, a decir verdad, diré que aparece ya en el $§ 1$ ). Pero ésta es una sombra para discutir en otra ocasión.
} 
yo (378) y, por ende, una realidad (en fin, toda realidad es — al menos - un estado del yo, el resultado de una limitación del yo). Como tal, como estado, el sentimiento carece de objeto.

Este sentimiento es, según Fichte, un impulso (Trieb) sentado como limitado o una limitación del impulso. Los sentimientos — de lo rojo, lo azul, lo dulce, lo salado (los ejemplos de Fichte en 375) — son desde el principio, en la Doctrina, expuestos como limitaciones del impulso que funcionan como posibilidades de acción, formando una esfera de acciones posibles (375). A esta concepción práctica —incluso, diríase, pragmática - obedece la preferencia de Fichte por Gefühl como germen de la conciencia, en lugar de la más tradicional $-\mathrm{y}$ kantianaEmpfindung (cf. EE, GA I/4, 243) ${ }^{12}$.

El paso a la consideración de la intuición (empírica) en el $\$ 7$ es el paso a la consideración de la actividad ideal que elevará a la conciencia ese estado. Sólo a consecuencia de esa elevación hay para la actividad un objeto propiamente hablando. Sin embargo, ese objeto no es un objeto ordinario o familiar. Fichte habla de una «materia originaria [Urstoff]» de la cosa, que no llega ni a cosa (Ding) ni a imagen (Bild) (390). El objeto de la intuición está entre el algo del sentimiento y la cosa del concepto (cf. 405 s.), es un algo no referido todavía a nosotros, en un sentido que hemos de aclarar.

El tema del $§ 8$ viene a ser entonces la referencia de ese algo al yo o al sujeto, porque en el intuir el yo se pierde en el objeto intuido y, así, no se capta propiamente como intuyente. Según las estipulaciones de Fichte, esa referencia significa la elevación de la intuición a concepto ${ }^{13}$. Por de pronto, hemos de entender

\footnotetext{
${ }^{12}$ Sobre el sentido en que Kant utiliza Gefühl o Empfindung, según si la representación que con estos términos se mienta está referida al sujeto o al objeto, ha de leerse su Crítica del Juicio, §3, B 8 s. (debo a Mariano Gaudio esta referencia).

${ }^{13}$ Hay una cierta tensión entre la caracterización del concepto en el $§ 8$ y la caracterización en el $\S 1$ : «Yo dirijo mi atención sobre el estado de reposo; en este reposo, lo que es en realidad algo activo se convierte en algo puesto; no permanece actividad, se convierte en un producto; pero no un producto diferente de la actividad misma, una materia, una cosa que habría precedido a la actividad del Yo, sino que simplemente el hacer (Handeln) es fijado porque es intuido; esto es lo que se llama concepto, en oposición a la intuición, que se dirige a la actividad como tal» (348; mi énfasis). Pero claro, allí el tema era el paso de la intuición intelectual al concepto, no de la empírica al concepto. El esclarecimiento de esto hay que buscarlo en el $§ 2$, donde se deduce la intuición del no-
} 
que lo que está en juego es la captación del carácter ideal del objeto o de toda experiencia. La elevación a concepto hace que la intuición venga acompañada por la conciencia del intuyente. Hasta ahora, la conciencia se hallaba o se sentía ligada o vinculada ( $\mathrm{u}$ "obligada») por la limitación y presentación (Darstellung) del objeto. Ahora, con la introducción del concepto, la conciencia pasa a verse como limitándose a un objeto, ateniéndose a un objeto, adecuándose a un objeto, concentrándose en él, entregándose a él (cf. 406). El § 8 ha de mostrar cómo el yo comparece precisamente para entregarse. Hasta ahora el yo estaba más bien perdido, abismado, engolfado en el que ha venido a ser el objeto intuido. A partir de ahora, se limita la limitación del yo y se la comprende como siendo un objeto entre otros.

Así pues, el tema del $\$ 8$ es el punto de unión entre lo objetivo, dado, inmediato del sentimiento y la intuición y lo, digamos, ponedor, limitador, ideal y libre, todo ello a la vez, de la concepción. En realidad, Fichte asume que en la conciencia común no hay sentimiento sin intuición ni intuición sin concepto. Y lo asume en su intento de comprender en qué sentido kantiano las intuiciones son en sí mismas "ciegas» y los conceptos son en sí mismos "vacíos». Pero la deducción fichteana, como la kantiana, ha de distinguir lo que en realidad no se da separadamente, aunque sí contraponiéndose (lo cual permite la toma de conciencia de su distinción).

Este punto de unión o, literalmente, de «unificación» (Vereinigungsgrund) es, por supuesto, el nudo de la entera Doctrina de la Ciencia. Es el punto de unificación de lo determinable y lo determinado del $§ 2$ y también el punto de unificación de lo real y lo ideal del $\S 3$, lo práctico y lo inteligente del $\$ 4$, la acción y la representación del $\$ 5$. Entender esa unificación como debe ser entendida no es, por tanto, tarea específica del $\S 8$. Si acaso, el $\S 8$ plantea con una crudeza aún mayor que los anteriores la dificultad que entraña tal pensamiento, amén de

yo: en 353 s. se explica que lo que es concepto - fijación, quietud - con respecto a la acción, de hecho, es acción con respecto al no-yo. O, con otras palabras: que lo que es concepto con respecto a la intuición primera es intuición con respecto al no-yo y, concretamente, «intuición externa» (en el bien entendido de que la intuición interna de Fichte no es empírica y, por tanto, es distinta de la que Kant llama de ese modo). La doctrina del concepto, por lo demás, no se clausura en el $\S 8$ tampoco (cf. $§ 12,430$ s.). 
apuntar a la única solución que el idealismo trascendental —al menos el de Fichte- considera satisfactoria.

En los términos de los $§ \S$ 6-8 el problema consiste en comprender la limitación de una actividad, la ideal, que es «ilimitable» de suyo (cf. 368; en 374 se habla de pensarla como móvil y sujeta a la vez). Hemos de comprender qué obliga a Fichte a concebirla de ese modo y cuál se sugiere que es el modo satisfactorio de pensar este aparente hierro de madera.

De lo primero, a mi entender, dan abundante cuenta las lecciones. La meditación esencial parece consistir en lo siguiente. Si la actividad ideal no fuera ilimitada (infinita), no podría 'ir más allá de (o trascender) su limitación y si no pudiera hacerlo, la limitación no sería tal o no sería una limitación para el yo. El carácter de la actividad ideal consiste en que se conserva (para mí) y no puede ser cancelada: se limita en un punto, pero puede desembarazarse de esa limitación (cf. $§$ 8, Observación C). Si estuviera limitada absolutamente, no sería apropiado decir que nota o permite la conciencia de la limitación («una resistencia no es nada sin actividad [o no la hay sin actividad] y en cuanto ella es superada llega al Yo", 369). Por otro lado, una actividad absolutamente ilimitada, que nada puede limitar (que por nada puede ser limitada) y a nada puede limitarse, no puede tener un objeto («todo lo que es intuible es algo que detiene», 367, cf. 369; «sólo puedo ser consciente de mi actividad, pero sólo puedo ser consciente de la misma como actividad limitada», 371).

Un modo de ilustrar este pensamiento puede ser éste. Imagínese un ojo abierto que no puede moverse y 've' constantemente (Kant diría: es afectado constantemente por) la luz que refleja una superficie roja, porque está, digamos, plantado o parado ante ella (en realidad no es esencial a la ilustración que la superficie tenga un único color ni que la superficie, por así decir, ocupe todo el campo visual del ojo, pero, claro, tampoco la frustra). Es un ojo para el que el rojo no tiene límites, que no puede, en efecto, 'ir más allá' del rojo. E imagínese un ojo, otro ojo, también abierto, que no puede dejar de moverse, que 've' constantemente una sucesión sin fin de manchas de color, ahora rojas, ahora no, sin poder, digamos, 'prestarles atención', contemplarlas morosamente o volver sobre ellas. La intuición de Fichte parece ser la de que ni el primer ojo ni el segundo pueden ver la superficie roja ni, en realidad, puesto que esa impotencia es generalizable, cualquier otra superficie. 
Su idea es que sólo la posibilidad de desembarazarse de una limitación o al menos combatirla o no aceptarla y, a la vez, sólo la posibilidad de adoptar una limitación, siquiera coyuntural y provisionalmente, permiten conjuntamente tener una relación con un objeto que constituye al objeto en objeto.

La consecuencia que Fichte extrae es que la única limitación que puede ser consciente ha de ser una limitación que la actividad ideal, a la que nada obliga absoluta o externamente, se da a sí misma o se autoimpone. En otros términos, la única limitación de la conciencia, propiamente hablando, es una limitación autónoma. $\mathrm{O}$, aún en otros, ha de ser el efecto de un concepto que la conciencia el yo, el sujeto- adopta como regla de conducta. «El Yo es libre y, sin embargo, se halla bajo leyes», se lee en la recapitulación con que concluye el § 8. «Esto sólo es posible porque el yo se sujeta a estas leyes con libertad» (403).

\section{Reflexión y autonomía}

Nótese que el contexto en que esto se indica es el de una aclaración de la representación (Vorstellung) y, a un tiempo, una deducción de la 'cosa' de la intuición: ya he dicho que los conceptos de los que en general trata el $\$ 8$ son conceptos empíricos, esto es, conceptos que nos hacemos de las «cosas» que sentimos. Atenerse a una ley, concepto o regla es, por tanto, por de pronto, atenerse a un modo de tomar las cosas, un modo de considerar aquello que padecemos, un modo de «interpretar» — si se me permite hablar así- qué posibilidades de acción quedan abiertas por los sentimientos.

Según el $§ 8$, por un lado, este atenerse nace de la libertad y, en ese sentido, no hay una norma o limitación que la actividad ideal deba aceptar necesariamente: en esto consiste, ya digo, la ilimitabilidad de la actividad ideal.

Ahora bien, ¿̨por qué este poder tomar las cosas de otro modo conviene que sea interpretado en los términos de la autonomía legislativa con que nos ha familiarizado Kant? Ésta es una cuestión que el $\$ 8$ deja pendiente. Quizá sea conveniente notar que las lecciones han contemplado otros modelos que aplicar para entender la relación entre lo determinable y lo determinado antes de que aflorara en 403 el modelo de la Crítica de la razón práctica. 
Al fin y al cabo, la posibilidad de trascender cualquier limitación puede parecer la posibilidad bruta de tomar siempre las cosas de otro modo o de reaccionar con otros pensamientos (aplicando otros conceptos). Y de hecho Fichte supone tal posibilidad y habla ocasionalmente de una elección no vinculada dentro de un espacio de posibilidades (cf. $§ 5,368$ ); tal espacio vendría a ser lo dado o condicionante, y la actividad ideal o libertad sería lo condicionado, que escoge entre posibilidades dadas (cf. § 6, 374) y, en este sentido, actúa «necesariamente» (375). No obstante, podría ser que esta discrecionalidad limitada entre posibilidades posibilidades, digamos, naturales o empíricas - no tenga por qué tomarse por un modelo rival al de la autonomía, ya que Fichte lo presenta de hecho como un modelo que no prejuzga si lo dado (lo determinable) procede del sentar de la actividad ideal (o que no se pueda decir que viene dado — dada en general la «esfera» en la que se elige— por «la naturaleza de la razón»).

Aún otro modelo que aparece en las lecciones es éste: en el reunir de lo múltiple consiste la libertad de elección, pero una vez que el concepto está proyectado (entworfen) y se actúa según él, las consecuencias de la actuación no dependen del concepto (370). Este otro modelo se fija en la facultad práctica como agente en efecto y no, digamos, como 'proyectante' o 'planificadora'.

El modelo que se favorece en el $\S 8$, ya digo, es en todo caso uno kantiano, que pretende dar sentido a la idea de coerción del pensamiento (Denkzwang) inmanente. En el lugar en que se hace explícito antes de la recapitulación final, Fichte escribe que hemos de entender esta coerción intelectual (que es la cara que en el parágrafo adopta la limitación o, mejor, el problema de comprender la limitación en el conjunto de la obra) — y, de su mano, el atenimiento a la verdadcomo atenimiento a «nuestro ser desde un punto de vista práctico».

Puede que valga la pena releer una vez más, completo, el párrafo en que esto se dice, el núcleo de la «Obervación B», tal vez el pasaje más interesante de todo el parágrafo:

"¿Pero soy realmente compelido a pensar las cosas de ese modo?

Puedo abstraer de ello o puedo pensar las cosas de otro modo, con lo cual no se daría esa coerción del pensamiento [Denkzwang]. Pero entonces no me represento la cosa según la verdad, porque si mi representación debe ser conforme a la cosa entonces ha de darse esa coerción del pensamiento. ¿¿Pero qué clase de 
verdad es esa a la que se atiene mi representación? Esta es la pregunta por la realidad que colocamos como fundamento de la representación. Nuestro propio ser en su aspecto práctico es esa verdad, es lo determinado inmediatamente, de lo que no podemos dar ningún fundamento ulterior. Ese propio ser nuestro lo interpretamos mediante una cosa fuera de nosotros. Esa cosa fuera de nosotros es presentada con arreglo a su verdad cuando está referida a un ser interior. A partir de un determinado QUANTUM de limitación en mí surge este o aquel QUANTUM de limitación fuera de mí» (401; soy responsable de las cursivas).

Al margen de la doctrina que una y otra vez se repite en el curso y aquí se reproduce al final (tanta limitación fuera de mí como limitación en mí), lo más interesante entre lo interesante es lo que se dice sobre «la pregunta por la realidad que colocamos como fundamento de la representación». La respuesta tiene dos caras - al menos - que conviene destacar, distintas creo, aunque no completamente ajenas la una a la otra y hasta cierto punto complementarias.

La posición de Fichte tiene por un lado un aspecto que podemos llamar 'antirrealista' y también 'leibniziano', dado que la realidad, la única realidad, a la que hay que atenerse o puede uno atenerse es nuestro ser en su aspecto práctico. Con este entendimiento concuerda en general la retórica, digamos, constructivista o productivista del idealismo fichteano, en la que el mismo $\$ 8$ incurre por lo menos otra vez, al principio, a propósito del origen de las alteraciones del sentimiento.

Por otro lado, frente a otros antirrealismos y frente al innatismo leibniziano en particular, Fichte hace valer la naturaleza práctica y, concretamente, moral de la fuente de toda determinación de la representación. Se dice que la realidad a la base de nuestra representación es del tipo de la de nuestro ser considerado prácticamente.

Ahora bien, ¿cuál es ese tipo? Y en fin: ¿qué es «nuestro ser en su aspecto práctico»? Lamentablemente la sección no ofrece clave alguna para entender esta expresión,

\footnotetext{
${ }^{14}$ No obstante, debería compararse con la de «mi ser originario» en 451 (cf. 453) y habría que aclarar su relación con el concepto de (mi) «individualidad» (461 y otras) y, por supuesto, explicarla por medio de la doctrina de una 'determinidad de un comienzo absoluto' (437), tareas todas, de la máxima importancia, que rebasan las posibilidades de este trabajo.
} 
que — si no me equivoco - aparece en el curso ahora por primera y última vez ${ }^{14}$. Esa clave, de todos modos, puede buscarse o más adelante en las lecciones (especialmente en los $\$$ 12-15: véase el resumen dictado del $\$ 12$ en 433 y el arranque del $§ 13$ allí mismo, así como el resumen del $§ 15$ en 464; pero dejo esa búsqueda para los comentaristas de esas partes) o en otros textos contemporáneos, como la Ética y, sobre todo, el escrito «Sobre el fundamento de nuestra fe en un gobierno divino del mundo», ambos de 1798.

En el resumen de sus puntos de vista que contiene este breve artículo, sobre todo de su convicción sobre el primado del punto de vista moral (o práctico) sobre el hombre y concretamente en la explicación de las consecuencias que tiene la conciencia del deber moral, a la que kantianamente se liga la conciencia de la libertad (de la que se asume un concepto también kantiano, pues se trata de la libertad «de todo influjo del mundo sensible»), Fichte aclara que hemos de asumir que podemos hacer lo que debemos hacer. Esto se expande diciendo que qué debemos hacer "es conocido por sí y verdadero por sí», que "no es fundamentado ni determinado por ninguna otra verdad; sino que todas las demás verdades son más bien determinadas por ésta» (üGuG, GA I/5, 352; cf. SSL, GA I/5, 43). Desde el punto de vista trascendental, que viene a ser el punto de vista filosófico o de la Doctrina y, también, el punto de vista de la actividad del yo teórico (que ve el mundo sensible como un producto de la limitación de esa actividad), los límites que organizan el mundo sensible - los contornos de los objetos empíricos, digamos - son por un lado incomprensibles o no deducibles en particular, pero por otro su «significado" es claro y cierto: «ellos son tu lugar determinado en el orden moral de las cosas». La conclusión de Fichte es que la coerción con la que se impone la fe - la creencia- en la realidad y los contornos de los fenómenos es una coerción moral (üGuG, GA I/5, 353), al menos en última instancia. Y un efecto de ella es que el mundo (sensible) sea concebido como «material [...] de nuestro deber» y los fenómenos aparezcan como constituidos por ese deber ${ }^{15}$.

\footnotetext{
${ }^{15}$ Este énfasis en la fe (o la creencia), en que el afán por entender y demostrar nos lleva hasta un punto en que creemos sin fundamento, reproduce el del admirado Jacobi. De hecho en las primeras páginas del manuscrito lo que parece reprochársele a Jacobi no es que haya partido de algo que no puede ser probado, sino que haya pensado que haciéndolo y abogando por ello se desentendía de proponer un principio (Grundsatz) de la filosofía (343 s.; cf. üGuG, GA I/5, 350).
} 
Por lo demás, que en el $§ 8$ hemos llegado al punto en que esa fe se ha explicado en buena medida es algo que el $§ 9$ confirma: «De este modo hemos llegado al verdadero carácter de la objetividad. Ahora sabemos de dónde viene que aceptemos cosas fuera de nosotros» (407). Si esto es así sólo en cierta medida es precisamente porque está por desarrollar el pensamiento de que el imperativo moral categórico es un principio de determinación de las limitaciones de la representación en general ${ }^{16}$.

Pienso que la coincidencia en los términos prueba la coincidencia en los tópicos $\mathrm{y}$, consiguientemente, justifica que un texto se interprete a la luz del otro ${ }^{17}$. "Nuestro ser en su aspecto práctico" parece ser, pues, nuestro lugar en el orden moral de las cosas (nuestro papel, digamos). Y si él es la única "verdad» a la que deben atenerse nuestros juicios es porque nuestros juicios sólo pueden aceptar el punto de vista de la realizabilidad de ese deber. Lo que sentimos e intuimos lo hemos de interpretar a la luz de ese deber, permitiendo el cumplimiento de cierto deber. Ése es el último límite absoluto de las cosas según nos las tomamos y la última fuente de coerción intelectual genuina. Podemos ir más allá de cualquier pensamiento, cambiarlo por otro o buscar para él un fundamento ulterior. Esas pesquisas y transformaciones han de respetar en todo caso la conciencia del deber particular en el mundo, cuya fuente presunta es la razón misma o, digamos, uno mismo en tanto que actor racional.

\section{Coerción intelectual y soberanía de lo conceptual}

Puede resultar más o menos obvio que el tratamiento que reciben sentimiento, intuición y concepto en los $§ \S 6-8$ responde al plan de mostrar la dependencia de la coerción intelectual de la conciencia del deber. En general, como dije arriba, un propósito explícito de los cursos sobre la Doctrina según el nuevo método fue mostrar cómo se podía y debía abordar a la vez el estudio del uso teórico y el uso práctico de la razón. La página del manuscrito en que ese propósito se airea (380) produce incluso la impresión de que la «vieja» Doctrina tenía por

\footnotetext{
${ }^{16}$ Véase el $\$ 12$, esp. 430, donde se habla de la objetivación del yo a través del concepto de fuerza, que hace posible el 'avistamiento' del mundo (alle Ansicht der Welt).

${ }^{17}$ Debo agradecer a Jacinto Rivera de Rosales la recomendación de este cotejo.
} 
tema la inteligencia, mientras ésta tiene por tema la libertad o la acción libre o, sin más, «lo práctico».

También queda claro en muchos lugares que el interés por el concepto en el $\S 8$ obedece al interés por el concepto como fin (o el concepto de un fin), al que se liga el concepto de acción libre. En la repetición a la vuelta de las vacaciones navideñas con las que se retoma el curso después del $§ 8$ leemos en efecto que si debemos sentarnos como agentes, hemos de ser conscientes del concepto de un fin, y que, después de haberse ocupado del concepto en general, las lecciones tratarán ahora de contestar la pregunta por la posibilidad de un concepto como ése.

Esa página proporciona el marco de interpretación del $§ 8$. Aunque el interés de la Doctrina sea en última instancia el de entender la acción, el querer, la libertad, Fichte considera que ha dado un tratamiento general a cuestiones como qué sea un concepto o en qué relación se hallan los conceptos con lo múltiple de la intuición o el sentimiento. De hecho la unidad de la doctrina que se reivindica a lo largo del curso la proporciona el hecho de que, insisto, todo suelo del mundo sensible o de la objetividad se liga a —o procede de — la conciencia de la propia acción libre iluminada por el imperativo de la moralidad. Puesto que esto es así, todo el significado de nuestras circunstancias y los objetos que las componen es práctico y, siendo práctico, es todo lo objetivo que se puede ser. Los sentimientos, intuiciones y conceptos de estos parágrafos no son sentimientos prácticos, intuiciones prácticas y conceptos prácticos, sino, sin más, sentimientos (recuérdese: de lo dulce, lo salado, etc.) e intuiciones y conceptos empíricos (cf. 430).

La idiosincrasia de los conceptos o, dicho de otro modo, lo que hace de nuestras representaciones conceptos es, según el parágrafo, que las intuiciones sean sentadas con conciencia de la libertad de la actividad ideal, es decir, con conciencia de que podemos 'ir más allá de ellas' (cambiando de sentimiento y objeto o modificándolo de algún modo). En el cuerpo del parágrafo, esta conciencia de la libertad procede de una intuición del yo que acompaña a la intuición del no-yo. El yo se intuye primero como base o denominador común de los sentimientos, es decir, como aquello que permanece o dura en el cambio del sentimiento o como el cambio o tránsito mismo (secciones 1-3 del $§ 8$ ), y luego se intuye como activo (secciones 5-6 y Observación C). En conjunto el parágrafo razona que la intuición del yo como activo sólo es posible por medio del sentimiento de una coer- 
ción y que, previamente, esta constricción lo es a una transformación determinada del sentimiento. La alteración del sentimiento se postula como necesaria (categórica) si hemos de concebir la posibilidad de la intuición del yo, agente ideal, sin que se indique de antemano cuál es la naturaleza o fuente de dicha alteración.

Que yo soy o estoy limitado en la intuición significa que estoy obligado a ordenar en ella lo múltiple así o asá y no de otro modo: "Que soy limitado en la intuición significa: en la intuición Y estoy obligado a organizar lo múltiple de ese modo y no de otro" (399). El sentimiento de la coerción es por tanto una condición de la autoconciencia (y por ende de la conciencia). Las observaciones al parágrafo, quizá su porción más interesante, exponen la doctrina general sobre la relación recíproca entre intuición del yo y el no-yo, sobre las que se anticipó algo arriba (en mis consideraciones preliminares).

La primera observación (A) indica que a la posibilidad de «ser para mí» le pertenece que haya cambios en mi naturaleza o estado, esto es, que algo le afecte. La tercera (C), por su parte, que el objeto que postulamos para explicar la limitación de nuestra actividad (para empezar práctica) sólo es algo estrictamente si reflexionamos sobre él, y ello libremente. La segunda (B), de la que he hablado ya con más detenimiento, señala que la última fuente de toda obligación, vinculación o limitación es, como hemos visto, moral (digamos, práctica-moral).

Ahora bien, ¿`cómo podemos entender la operación de esa limitación?, ¿cómo, de hecho, que nuestro lugar en el orden moral sea lo último que determina a qué deben atenerse nuestros juicios sobre las cosas? Para empezar, Fichte tiene claro que la síntesis entre libertad y limitación que da pie a los objetos, esto es, la síntesis determinada de lo múltiple por medio de la cual la intuición gana su objeto (o se hace vidente), puede ser o no ser emprendida. Él reconoce la necesidad de explicar una limitación particular del sentimiento sentando un objeto (Y) determinado. Pero no reconoce la necesidad de explicar una limitación particular del sentimiento.

En la reconstrucción de la tercera observación se parte de la existencia de limitaciones prácticas que se alteran o transforman, sobre las cuales, si reflexiono, se levanta la intuición de mí mismo, que, como intuición de lo limitado, empuja a postular un objeto limitador. Pero la limitación del sentimiento, según Fichte, 
es sentada (o puesta) desde el principio «con libertad», de modo que «el sentimiento mismo depende de la libertad» y, concretamente, de la libertad de la reflexión (403; cf. 504).

Que todo depende de la libertad es, desde luego, la tesis principal del sistema de Fichte, en todas sus versiones originales. En la Ética esta dependencia se expresa asimismo como dependencia en que se halla el 'ser' con respecto al concepto (cf., por ejemplo, SSL, GA I/5, 51) o la razón (cf. SSL, GA I/5, 68 s.), pensados ellos a su vez, ciertamente, como absolutamente autónomos y, además, soberanos (recuérdese: puesto que debo, puedo). Y también indicando que la libertad no es sólo el principio de toda moralidad, sino también un principio teórico.

A la luz del estudio de los avatares de la crítica del empirismo en el siglo XX, como es obvio directa e indirectamente inspirada en la crítica del empirismo de Kant y sus sucesores, uno puede verse tentado a interpretar la doctrina fichteana de la coerción intelectual (y la relativa falta de ella) como si aquí se avanzara un concepto pragmatista de la experiencia y de la verdad. Y, de hecho, es hoy corriente entrever ese concepto en la crítica hegeliana del empirismo - inspirada en la obra de Fichte y Schelling - y hay incluso quien lo ha retrotraído explícitamente a la Doctrina de la Ciencia $^{18}$. No obstante, quisiera acabar mi comentario recomendando cierta cautela en este punto.

La autonomía o «soberanía» de lo conceptual en la crítica de Wittgenstein, Quine, Sellars y sus sucesores al empirismo en los años 1950 y 1960 se asocia a la convicción, por un lado, de que hay de hecho coerción de nuestra representación — por decirlo en los términos de Fichte- sin que esa coerción prejuzgue qué movimientos en términos de creencias abrazadas y abandonadas nos fuerza a realizar la coerción. Por otro, en que las normas a las que sí han de atenerse esos movimientos han de ser explicadas en los términos de otras

\footnotetext{
${ }^{18}$ Estoy pensando, en el primer caso, sobre todo en los comentarios de Robert Brandom a la Fenomenología del Espiritu (en, por ejemplo, "Some Pragmatist Themes in Hegel's Idealism: Negotiation and Administration in Hegel's Account of the Structure and Content of Conceptual Norms", en: European Journal of Philosophy, 7/2, 1999, pp. 164-189) y, en el segundo, en un estudio de Robert Pippin titulado «Fichte's Alleged Subjective, Psychological, One-Sided Idealism» (en: Sally Sedgwick [ed.], The Reception of Kant's Critical Philosophy. Fichte, Schelling, and Hegel, Cambridge, Cambridge University Press, 2000, pp. 147-170).
} 
creencias y reglas aceptadas. Uno puede hablar de limitaciones, impulsos o empellones - Anstöße - con los que el mundo de alguna manera condiciona $\mathrm{u}$ ocasiona la actividad de la inteligencia. Pero no puede decir que se le imponen 'desde fuera' opiniones o conceptos. Como diría Quine, los conflictos entre mis creencias y mis experiencias mantienen ligámenes sólo indirectos con mis creencias. No hay experiencias singulares que sean «responsables» de creencias singulares. Todo movimiento doxástico, por decirlo así, es un movimiento en el espacio de las razones (como dice Sellars) y, por tanto, responde únicamente ante la existencia actual y futura de potenciales justificaciones.

Mis recelos son de dos clases. Por un lado, el contexto amplio en que Fichte trata de hacer inteligible la coerción intelectual es un contexto que hoy podría denominarse metaético, en el que la referencia a los imperativos morales en general, como hemos visto, sirve como guía, por cierto última, para la determinación de la verosimilitud de los juicios teóricos. Fichte no dice que la única norma a la que han de atenerse esos juicios viene proporcionada por otros juicios de la misma índole que están siendo dados por sentados. En este punto, pues, él no parece defender lo que Donald Davidson ha bautizado una «teoría de la coherencia» de la verdad y el conocimiento (aunque adopte algún tipo de "holismo»; cf. 451). El imperativo categórico kantiano es el fundamento (último) de la verosimilitud de todo juicio teórico sobre lo que puede ser hecho en cada circunstancia.

Con esto no quiero decir, no obstante, que Fichte sólo reconozca una de las leyes que sobrecogen a Kant: sí la ley impresa en nuestro corazón, pero no la ley que gobierna el cielo estrellado sobre nuestras cabezas. También él habla de «leyes de la intuición» (432) —y no sólo, pues, de leyes morales-, a las que nos mantiene sujetos nuestra naturaleza sensible (sinnlich). Y, de hecho, la advertencia de una causalidad de la naturaleza es una reconocida condición de la conciencia en general, incluida la conciencia de nuestro propio actuar (por razones que no pueden ser expuestas aquí; cf. 427 y SSL, GA I/5, § 8). Lo que quiero decir con lo anterior es, más bien, que desde el punto de vista trascendental, siempre según Fichte, hemos de preguntarnos por la explicación de las leyes determinadas de la naturaleza (leyes que la conciencia común - y, podríamos decir, el naturalismo contemporáneo común- acepta en su determinación como hechos o, digamos, super-hechos últimos; Fichte diría: como cosas en sí o leyes de una naturaleza 'fuera de nosotros') y que la respuesta que hay 
que dar es la siguiente: «es el Yo mismo el que se limita de esta forma [de acuerdo con esas leyes y el orden de los medios que preestablecen], pero no con libertad y albedrío, pues entonces no estaría limitado, sino a consecuencia de una ley inmanente de su propio ser, por una ley natural de su propia naturaleza (finita)» (SSL, GA I/5, 101 ${ }^{19}$ ), ley que marca una disposición original particular en el mundo (y del mundo) del ser racional particular y es, en mi lectura del $§ 8$, la fuente última de toda determinación teórica de la facultad de representar.

Por otro lado, la crítica a la idea misma de una certeza sensible inmediata de Hegel, que esos críticos del empirismo del siglo pasado continúan a su modo, va dirigida también contra Fichte, y de hecho Fichte matiza su énfasis en la autonomía de lo teórico con la referencia, que aparece en momentos clave de los escritos teóricos de los años 1790, a lo absolutamente contingente o "puramente empírico» del sentimiento (EE, GA I/4, 243). Fichte tilda a quienes pasan por alto esto de idealistas "trascendentes», y a quienes acusan a su Doctrina de hacerlo, de haberla malentendido. En las lecciones nova methodo aparece también el compromiso con la determinación cognoscible intrínseca de lo sensible en un pasaje del $\S 6$ en que se lee: «no puedo decir dónde acaba el rojo», que lleva a Fichte a decir que este algo - lo rojo, etc.- - y la conciencia del mismo es aquello de lo que parte toda acción o lo dado como esfera de la acción posible (375; cf. 418, 424, 433, 440; en estos lugares el sentimiento, junto a la voluntad, es considerado lo inmediato no deducible conceptualmente). Creo, por ello, que hay que reconocerle a Fichte precisamente el compromiso con un 'grano' de empirismo, con algo después de todo dado (y contingente) contra lo cual la semántica filosófica pragmatista de Quine, Sellars y Wittgenstein se volvió hace sesenta años. Sellars retrotrae ese grano o germen a la suposición del empirismo clásico de una capacidad natural de discriminar cualidades sensibles y ser consciente de ellas. Yo, por mi parte, diría que Fichte presumió siempre que gozábamos de dicha capacidad y conciencia ${ }^{20}$.

\footnotetext{
${ }^{19}$ El editor español de la Ética advierte que en este punto brilla «el aspecto más 'monadológico' del Yo fichteano», con el que una defensa contemporánea del punto de vista trascendental de Fichte, pienso yo, habrá de vérselas y deseárselas.

${ }^{20}$ La conclusión de Hegel en la Fenomenología es explícitamente que el idealismo trascendental (de Kant y Fichte) es un «empirismo».
} 


\section{Consideraciones finales}

(1) Tal vez después de todo sea inevitable hacer una interpretación 'extravagante' de la doctrina de que toda coerción intelectual es, en última instancia, moral o derivada de la moral. En la Ética, al fin y al cabo, Fichte intenta razonar la compatibilidad de la doctrina de la libertad de elección (Wablfreiheit) con la doctrina leibniziana de una armonía preestablecida de las representaciones (SSL, GA I/5, 205 ss.; su solución tiene que ver, por cierto, con la concepción de un «extraer [herausgreifen] de una medida de seres racionales en general», del que se habla en la Doctrina nova methodo; cf. 468, 470, 503, 509²1). Si después de todo la libertad del yo es compatible con la necesidad de la armonía, quizás sea más aparente que otra cosa la posibilidad de tomar las cosas — siempre- de otro modo.

(2) El $§ 8$ es una sección de transición. El único «teorema» que le es exclusivo reza: no hay autoconciencia (ni conciencia) sin alteración del sentimiento. Pero su interés, a mi juicio, no se reduce al de ese teorema, con el que es difícil no simpatizar. Por las razones ofrecidas, lo encuentro sobre todo en los juicios sobre la fuente de la coerción intelectual: la determinación (Bestimmung) de nuestro ser desde un punto de vista práctico — moral en definitiva — es la fuente de toda limitación del pensamiento. Es más difícil simpatizar con este reduccionismo, pero es obligatorio reconocer el valor central que adquiere en el sistema fichteano, un sistema consagrado a comprender el carácter de principio absoluto de toda acción y representación que puede tener, tal vez tiene, la libertad.

21 «No parece, pues, que las lecciones que registra Krause sean ésas en las que este argumento de la Ética habría sido abandonado, según cuenta Fichte años después (cf. GA III/4, 313 s.). Jacinto Rivera de Rosales sugiere, a la vista de las "explicaciones" al respecto de Reinhard Lauth (en GA II/2, 12 s.), que la enmienda debió ocurrir en las lecciones sobre Ética de 1798-1799 (cf. su edición de J. G. Fichte, Ética, Madrid, Akal, 2005, p. 263). En todo caso, Fichte dice haber rectificado el argumento. Nada indica que el problema que notó en la Ética se haya disipado». 